\title{
PRESCRIÇÕES HISTORIOGRÁFICAS E A POÉTICA ROMÂNTICA: REFLEXÕES SOBRE A OBRA DE GONÇALVES DIAS
}

\section{HISTORIOGRAPHICAL PRESCRIPTIONS AND ROMANTIC POETICS: REFLECTIONS ON THE WORK OF GONÇALVES DIAS}

Mateus Robaski Timm*

\section{Antônio Hohlfeldt ${ }^{* *}$}

PUCRS

Resumo: Este artigo pretende, num primeiro momento, cotejar as opiniões dos primeiros historiadores da literatura que se debruçaram sobre a produção literária brasileira. Tais historiadores recomendavam, sobretudo, o abandono das convenções estéticas em vigor na Europa, para que fossem adotados temas verdadeiramente brasileiros, como os relativos aos povos autóctones e à natureza americana. Num segundo momento, este artigo buscará mostrar como Gonçalves Dias seguiu apenas em parte as prescrições dos primeiros historiadores da literatura brasileira. O poeta maranhense introduziu temas nacionais, no entanto, não abandonou plenamente o uso de convenções clássicas de origem europeia. Por fim, este artigo, refletirá sobre a produção indianista de Gonçalves Dias, como este viés composicional buscou sublimar os povos autóctones, ao mesmo tempo em que procurava estabelecer um passado para a nação que acabara de se emancipar. Assim, este trabalho pretende mostrar como Gonçalves Dias foi um grande poeta capaz de aliar tradição e inovação numa obra relativamente extensa. As interpretações de Antonio Candido e de Nelson Werneck Sodré deixam isto claro: Gonçalves Dias foi um poeta romântico que soube aproveitar o que ainda possuía vigor na estética neoclássica.

Palavras-chave: Gonçalves Dias. Historiografia da literatura brasileira. Romantismo. Neoclassicismo. Indianismo.

Abstract: This article intends, in a first moment, to compare the opinions of the first historians of the literature that have been focused on the Brazilian literary production. Such historians recommended, above all, to leave out the aesthetic conventions in force in Europe, so that truly Brazilian themes, such as those related to autochthonous peoples and American nature, were adopted. Secondly, this article will seek to show how Gonçalves Dias followed only in part the prescriptions of the first historians of Brazilian literature. The poet from the state of Maranhão introduced national themes, however, did not completely abandon the use of classical conventions of European origin. Finally, this article will reflect on Gonçalves Dias’

\author{
* Mestrando em \\ Teoria da Literatura \\ pela Pontifícia \\ Universidade Católica \\ do Rio Grande \\ do Sul (bolsista \\ CNPq). E-mail: \\ mateustimm@ \\ outlook.com \\ ** Doutor em Letras \\ pela Pontifícia \\ Universidade \\ Católica do Rio \\ Grande do Sul. \\ E-mail: hohlfeldt@ \\ pucrs.br
}


indianist production, in what way this compositional bias sought to sublimate the autochthonous peoples, while at the same time trying to establish a past for the nation that had just emancipated itself. Thus, this work intends to show how Gonçalves Dias was a great poet able to combine tradition and innovation in a relatively extensive work. The interpretations of Antonio Candido and Nelson Werneck Sodré make this clear: Gonçalves Dias was a romantic poet who knew how to take advantage of what still had vigor in neoclassical aesthetics.

Keywords: Gonçalves Dias. Historiography of Brazilian literature. Romanticism. Neoclassicism. Indianism.

\section{Considerações iniciais}

Antonio Gonçalves Dias (1823-1864) é conhecido, sobretudo, pela sua atividade poética que inseriu temas nacionais na incipiente literatura brasileira. Por conta disto, o poeta maranhense foi um dos responsáveis pela consolidação de uma nova vertente da literatura brasileira, através do Romantismo, mesmo não tendo abandonado por completo elementos da poesia neoclássica. Pertencendo ao movimento romântico, as suas “poesias americanas" buscaram trazer elementos da geografia do "Novo Mundo" e da cultura indígena para a literatura: lendas, mitos, práticas e os próprios povos autóctones aparecem sublimados em diversos poemas de Gonçalves Dias. Este seu lado nacionalista parece responder à atividade crítica de historiadores da literatura, como Friedrich Bouterwek, Ferdinand Denis e Almeida Garrett, que apontaram caminhos para o futuro da poesia brasileira: afastar-se da matriz poética europeia, para desenvolver temas, imagens, composições verdadeiramente brasileiras.

Assim, este trabalho busca estudar, num primeiro momento, as consonâncias e as dissonâncias das opiniões encontradas nos primeiros historiadores da literatura brasileira acerca da situação das letras nacionais no final do século XVIII e início do século XIX. O pensamento de tais historiadores desencadeiam algumas reflexões sobre a especificidade de Gonçalves Dias dentro do incipiente sistema literário brasileiro. Além disso, busco perceber os elementos composicionais da obra do poeta maranhense. Desta maneira, procuro interpretar o que há de inovação romântica e de variação neoclássica nos seus poemas. Por fim, detenho-me no indianismo, procurando caracterizar tal concepção de literatura.

\section{Historiadores da literatura: crítica e prescrição}

Para analisar o que há de inovador em Gonçalves Dias, dentro do sistema literário ocidental, mostra-se interessante um percurso através dos textos que primeiro buscaram pensar sistematicamente a literatura brasileira. Trata-se de textos exordiais em que historiadores da literatura europeus, 
salientam, sobretudo, a falta de originalidade dos primeiros poetas brasileiros. Contextualizando o trabalho destes historiadores da literatura estrangeiros, Guilhermino César (1978, p. XVI) explica que "a historiografia literária, estimulada pelo impulso inovador do Romantismo, articulava-se em sistema, lançava métodos, defendia postulados nacionalistas, revia o passado à luz de critérios que tanto valorizavam o povo quanto o indivíduo”. Assim, desejosos de que a contribuição brasileira enriquecesse as letras ocidentais, tais historiadores criticam, apontam e elogiam, seguindo um padrão de gosto estético que valoriza o uso da cor local, através da descrição da natureza e dos costumes americanos, e desvaloriza o emprego de convenções literárias europeias, na poesia então incipiente.

O primeiro historiador literário que escreveu algumas linhas sobre a literatura brasileira foi Friedrich Bouterwek. Este pesquisador alemão critica Cláudio Manuel da Costa por não renovar a poesia com imagens inéditas. Falando sobre as éclogas de Costa, Bouterwek (1978, p. 11) censura: “foram compostas com especial meticulosidade, e não lhes faltam passagens excelentes; mas, a exemplo da maioria das éclogas portuguesas, são, em parte, poesia de ocasião, de caráter bucólico”. Trata-se de uma crítica à escrita poética valendo-se de elementos da tradição classicista, que já se encontrava desgastada. Tal apreciação negativa é ampliada por Simonde de Sismondi (1978, p. 25), outro historiador da literatura do século XIX: "não se pode ver sem espanto essa ideia fixa da poesia pastoril que persegue os portugueses desde o século XII até nossos dias, dando a toda a sua literatura um quê de infantil, enjoativo e amaneirado”. O português Almeida Garrett ainda reforça a falta de originalidade de Cláudio Manuel da Costa e de outros primeiros poetas brasileiros, lamentando a falta de "espírito nacional”:

E agora começa a literatura portuguesa a avultar e enriquecer-se com as produções dos engenhos brasileiros. Certo é que as majestosas e novas cenas da natureza naquela vasta região deviam ter dado a seus poetas mais originalidade, mais diferentes imagens, expressões e estilo, do que neles aparece: a educação europeia apagou-lhes o espírito nacional: parece que se receiam de se mostrar americanos; e daí lhes vem uma afetação e impropriedade que dá quebra em suas melhores qualidades. (GARRETT, 1998, p. 57).

Na opinião crítica de Simonde de Sismondi e de Almeida Garrett, Cláudio Manuel da Costa não é um grande poeta por ter se valido pouco, na criação literária, de elementos composicionais diversos dos utilizados na cultura europeia. Por outro lado, para o francês Sismondi (1978), o poeta Manuel Inácio da Silva Alvarenga acertou esteticamente ao utilizar um léxico e imagens propriamente americanas:

Ao cabo de tudo, o principal atrativo desses poemas é ainda a sua cor local, as imagens sugeridas pelas árvores, pelas borboletas, pelas serpentes da América; ou o convite para mitigar os calores de dezembro nas frescas 
ondas de um regato. Lendo os primeiros poemas escritos em regiões tão afastadas de nós, pensamos mais no que eles prometem do que no que efetivamente nos dão. (SISMONDI, 1978, p. 26).

Se Bouterwek e Sismondi, historiadores da nossa embrionária literatura, censuram a pouca inovação dos poetas brasileiros sem, no entanto, sugerirem um novo percurso estético a trilhar, o francês Ferdinand Denis procurou apontar um caminho a ser percorrido. "Considerações gerais sobre o caráter que a poesia deve assumir no Novo Mundo”, subtítulo da história da literatura de Ferdinand Denis, evidencia claramente a sua proposta. O historiador literário francês começa com o postulado de que “o Brasil experimenta já a necessidade de ir beber inspirações poéticas a uma fonte que verdadeiramente lhe pertença”. (DENIS, 1978, p. 36). A seguir, recomenda a rejeição da poética greco-latina, para que viceje uma poesia nova, própria do continente americano. Esta nova poesia estará amparada pela natureza exuberante e pelas fábulas dos povos autóctones:

Se essa natureza é mais esplendorosa que a da Europa, que terão, portanto, de inferior aos heróis dos tempos fabulosos da Grécia esses homens de quem não se pode arrancar um só lamento, em meio a horríveis suplícios, e que pediam novos tormentos aos seus inimigos, porque os tormentos tornam a glória maior? Seus combates, seus sacrifícios, nossas conquistas, tudo apresenta aspecto esplendoroso. (DENIS, 1978, p. 37).

Além de Ferdinand Denis, o português Almeida Garrett (1998) é outro historiador literário que, ao analisar a obra Marília de Dirceu, de Tomás Antônio Gonzaga, aponta enfaticamente uma direção desejável para a jovem poesia brasileira:

Se houvesse por minha parte de lhe fazer alguma censura, só me queixaria, não do que fez, mas do que deixou de fazer. Explico-me: quisera eu que em vez de nos debuxar no Brasil cenas da Arcádia, quadros inteiramente europeus, pintasse os seus painéis com as cores do país onde os situou. Oh! E quanto não perdeu a poesia nesse fatal erro! Se essa amável, se essa ingênua Marília fosse, como a Virgínia de Saint-Pierre, sentar-se a sombra das palmeiras, e enquanto lhe revoavam em torno o cardeal soberbo com a púrpura dos reis, o sabiá terno e melodioso, - que saltasse pelos montes espessos a cotia fugaz como a lebre da Europa, ou grave passeasse pela orla da ribeira o tatu escamoso, - ela se entretivesse em tecer para o seu amigo e seu cantor uma grinalda não de rosas, não de jasmins, porém dos roxos martírios, das alvas flores dos vermelhos bagos do lustroso cafezeiro; que pintura, se a desenhara com sua natural graça o ingênuo pincel de Gonzaga! (GARRETT, 1998, p. 58).

Na visão destes historiadores da literatura, a natureza europeia já estava desgastada, seja a verdadeira, seja a imaginada. Por isso, a poesia que levasse em conta a pujança ambiental da América renovaria a literatura: os 
poetas que a configurassem literariamente, na opinião de Ferdinand Denis, por exemplo, logo acabariam sendo mestres dos europeus. Em análise do Caramuru, de Santa Rita Durão, fica evidente a proposta do historiador francês de incentivar, nas produções brasileiras, o abandono dos elementos da cultura europeia em proveito dos americanos; atitude seguida em parte por Santa Rita Durão, por ser predominante a cor local na sua composição épica, além de exibir os costumes e práticas dos povos autóctones. Comentando essa escolha estética, presente no Caramuru, Ferdinand Denis (1978, p. 47) adverte que "os americanos não têm feito sentir em suas poesias o influxo da natureza que os inspirou; antes da Independência, parecia até pretenderem olvidar a própria pátria para pedir à Europa um quinhão da sua glória”. A necessidade de apresentar uma poesia original se faz premente para que o Ocidente tenha uma noção da natureza e dos povos remanescentes no território brasileiro e, na opinião de Ferdinand Denis, Santa Rita Durão satisfez tal proposta: "julguei-me obrigado a analisar a obra de Durão, porque reveste caráter nacional, apesar de suas imperfeições, e assinala claramente o objetivo que deve dirigir-se a poesia americana”. (DENIS, 1978, p. 57).

Igualmente elogiada por Ferdinand Denis (1978, p. 58) é a presença da natureza americana em $O$ Uraguai de Basílio da Gama, em que há "hábil descrição do Novo Mundo, onde vastas planícies se distendem, onde a natureza é tão irregular na sua produtividade e opulenta nas provisões, cobrindo de pastagens o espaço que não reserva as florestas”. No entanto, o historiador francês lamenta que Basílio da Gama não tenha escrito mais sobre a história da civilização jesuíta das missões, que certamente agradaria os leitores europeus. Além disso, na sua história literária, Ferdinand Denis está de acordo com as críticas de Friedrich Bouterwek e Sismonde de Sismondi quanto ao emprego de temas europeus na poesia de Cláudio Manuel da Costa. Assim, o árcade mineiro teria exagerado na utilização de elementos mitológicos de convenção, ao invés de ter buscado, de forma original, o ambiente americano.

Entrementes, Gonçalves de Magalhães no seu “Discurso sobre a história da literatura brasileira” reitera as críticas quanto à apropriação do caráter europeu na poesia de origem brasileira. Falando sobre o desenvolvimento dessa arte no território nacional, Magalhães se queixa da não apropriação de elementos locais, em favor do ideário europeu:

Com a poesia vieram todos os deuses do paganismo, espalharam-se pelo Brasil, e dos céus, e das florestas, e dos rios se apoderaram. A poesia brasileira não é uma indígena civilizada; é uma Grega vestida à francesa e à portuguesa, e climatizada no Brasil; é uma virgem de Hélicon que, peregrinando pelo mundo, estragou seu manto, talhado pelas mãos de Homero, e sentada à sombra das palmeiras da América, se apraz ainda com as reminiscências da pátria, cuida ouvir o doce murmúrio da castalia, o trépido sussurro do Lodon e do Ismeno, e toma por um rouxinol o sabiá que gorjeia entre os galhos de laranjeira. (MAGALHÃES, 1974, p. 20). 
Não obstante a crítica às primeiras obras poéticas nacionais, Gonçalves de Magalhães tem a certeza de que a escrita literária brasileira se voltará para o que é propriamente seu pelo fato do homem possuir um "instinto oculto”, que produzirá poemas brasileiros devido a um "caráter de necessidade”, ou então, através da “ordem providencial ou natureza das coisas”. Além da exuberante natureza, em sua opinião, superior em todos os aspectos à europeia, o poeta que desejasse ser "nacional” deveria voltar-se para o passado, quando os povos que habitavam o território, pela sua capacidade de canto, eram tão profícuos nesta arte quanto os trovadores medievais, lamentando que não tivessem sido recolhidos as suas canções que certamente, na opinião de Gonçalves de Magalhães, teriam influenciado muito na futura poesia brasileira. Contudo, Magalhães (1974, p. 26) não é um radical em suas opiniões quanto ao emprego de referências da cultura greco-latina, como fica claro na seguinte passagem do "Discurso sobre a História da Literatura do Brasil": "convém, é certo, estudar os antigos e os modelos dos que se avantajaram nas diversas composições poéticas, mas não escravizar-se pela cega imitação”.

\section{Gonçalves Dias: um romântico neoclássico}

Antonio Gonçalves Dias parece ter levado em consideração as críticas dos historiadores literários citados, pois a sua poesia, sobretudo pela estética indianista, traz fôlego novo para o mundo das letras ocidentais. O poeta buscou versejar sobre temas brasileiros e os seus poemas estão impregnados pela cor local, trazendo imagens de alta qualidade estética sobre a natureza e o passado nacionais. Entretanto, Gonçalves Dias não renegou a tradição neoclássica, mas se valeu dela em alguns aspectos, como na valorização da simplicidade, harmonia e clareza, elementos composicionais presentes em muitos dos seus versos, sem, no entanto, utilizar, na escrita de seus poemas, as figuras e os espaços mitológicos de matriz europeia.

Antonio Candido, na sua Formação da literatura brasileira, já com uma visão historicamente distanciada, assegura e sublinha o fundamental papel de consolidador do Romantismo no Brasil que Gonçalves Dias exerceu. Candido (2013, p. 401), fazendo um panorama da atividade poética de Gonçalves Dias, diz que ele “vincula-se ao grupo de Magalhães não só pelas relações e o intuito nacional, como pelo apego à harmonia neoclássica, que herdou dos setecentistas e primeiros românticos portugueses”. Além disso, Gonçalves Dias se afasta dos novos poetas românticos por não escrever versos pessimistas, nem ceder à intempestividade sentimental: é poeta “sóbrio e elegante, embora não seja menos forte na expressão nem menos rico na personalidade”. (CANDIDO, 2013, p. 401). Assim, num tempo de excessos literários, de uma poética realizada pelo transbordamento emocional, Gonçalves Dias organizava a sua arte pela medida equilibrada, para transparecer certa aurea mediocritas afetiva e artística. Logo, a conjugação 
da expressão patética romântica com um poetar equilibrado é um dos traços distintivos da obra de Gonçalves Dias.

Se o debate girando em torno da renovação da poesia brasileira, difundido pelos grupos constituídos em torno das revistas Niterói (1836) e Minerva Brasiliense (1843-1845), ou seja, correspondendo a uma opinião vigente na primeira metade do século XIX, apontara Gonçalves de Magalhães como reformador da literatura brasileira, por ter iniciado aqui o novo estilo, já em meados do século XIX, Gonçalves Dias é erigido criador da literatura nacional. Esta é a opinião de Álvares de Azevedo, Macedo Soares, Fagundes Varela, Almeida Braga, Machado de Assis, Alexandre Herculano, que, de alguma forma, de poesias a artigos, prestaram homenagem e reconheceram o gênio do poeta maranhense. Por causa desta grande repercussão "nele as novas gerações aprenderam o Romantismo. Sob este ponto de vista foi o acontecimento decisivo da poesia romântica e todos os poetas seguintes, de Junqueira Freire a Castro Alves, pressupõem a sua obra”. (CANDIDO, 2013, p. 403).

Gonçalves Dias trabalhou poeticamente em profundidade. Além da sua tão elogiada poesia indianista e nacional, versejou temas como a saudade, a melancolia, a natureza... Vendo desta maneira, os topoi antes citados integram-se numa constelação que não conhece fronteiras literárias. Portanto, mesmo que a crítica tenha privilegiado o Gonçalves Dias indianista e nacional, os poemas que versam sobre a natureza são interessantes por relacionar um significado profundo e um registro da realidade, como nas duas últimas estrofes do poema "Consolação nas lágrimas”:

O azul do céu, nem da lua

A doce luz refletida,

Nem o mar beijando a praia,

Nem a terra adormecida,

Nem meigos sons, nem perfumes,

Nem a brisa mal sentida,

Nem quanto agrada e deleita,

Nem quanto embeleza a vida;

Nada é melhor que este pranto

Em silêncio gotejado,

Meigo e doce, e pouco e pouco

Do coração despegado;

Não soro de fel, mas santo

Frescor em peito chagado;

Não espremido entre dores,

Mas quase em prazer coado!

(DIAS, 1941, p. 133). 
Há também inúmeros poemas, na obra de Gonçalves Dias, que se alinham com um estoicismo que percebe a vida como superação ininterrupta de padecimentos, onde a tristeza inerente à existência é apaziguada pelo refinamento da arte. Exemplo disso são estas estrofes do poema "Inocência":

\author{
Corre a vida pressurosa, \\ como a rosa, \\ Como a rosa na corrente. \\ Amanhã terás amor? \\ Como a flor, \\ Como a flor fenece a gente.
}

Hoje ainda és tu donzela

Pura e bela,

Cheia de meigo pudor;

Amanhã menos ardente

De repente

Talvez sintas meu amor.

(DIAS, 1941, p. 46).

Neste sentido, como exemplifica as estrofes destes dois poemas, a obra de Gonçalves Dias não se esgota na temática indianista. Sobre isso, Nelson Werneck Sodré (1964, p. 283) sintetiza que “o índio e a natureza são os seus dois grandes temas, como ocorre com todos os indianistas e com a maioria dos românticos. Mas sabe cantar também a saudade, o exílio, o mal de amor, com uma força que poucas vezes a língua conheceu tão grande”. Entrementes, também é peculiar ao poeta maranhense fundir emoções que independem do cenário, por fazerem parte das convenções poéticas da cultura ocidental, com personagens autóctones que as sentem. Assim, a ameríndia aguarda pelo seu amado, no poema "Leito de folhas verdes", enquanto medita sobre o imperceptível fluir do tempo, nos momentos de angústia da espera amorosa. Esta composição, que apresenta as suas singularidades americanas, no entanto, não está alheia aos grandes temas da lírica ocidental, que nela se renovam, como fica evidente na seguinte estrofe:

Por que tardas, Jatir, que tanto a custo

À voz do meu amor moves os passos?

Da noite a viração, movendo as folhas, Já no cimo dos bosques rumoreja.

(DIAS, 1941, p. 284). 
Outro traço que permite perceber a variedade da obra de Gonçalves Dias consiste em sua valorização de elementos da poética neoclássica. Como o fato de alguns de seus poemas possuírem uma configuração prosaica. Deste modo, para alcançar composições de sentido claro, houve “ausência de embriaguez musical, [levando-o] a cultivar o verso discursivo, sentencioso, que se distingue muito mais dificilmente da prosa, quando falta a verdadeira tensão poética”. (CANDIDO, 2013, p. 413). Tal característica, a busca pela clareza de sentido, pode ser percebida em “Amor delírio - engano”, onde a simplicidade da frase, quase prosaica, não cria imagens de complexa compreensão:

E eu sempre a via!... quer nas nuvens d'oiro,

Quando ia o sol nas vagas sepultar-se,

Ou quer na branca nuvem que velava

O círculo da lua, - quer no manto

D’alvacenta neblina que baixava

Sobre as folhas do bosque, muda e grave,

Da tarde no cair; nos céus, na terra,

A ela, a ela só, viam meus olhos.

(DIAS, 1941, p. 58).

Estes versos entram em sintonia com a opinião de Nelson Werneck Sodré (1964, p. 283), quando diz que Gonçalves Dias “versejou com segurança no dizer, com uma técnica singular, ao mesmo tempo culta, porque ancorada no que o clássico e o antigo têm de mais puro, o que é essencial neles, e simples, porque apta a chegar a todos os corações”. Sem perder-se nos excessos românticos, nem conter-se nos rigores arcádicos, Gonçalves Dias conjugou as duas estéticas, mas sendo plenamente romântico, já que o que há de neoclássico na sua poesia é proveniente de uma impregnação de valores clássicos presentes na cultura. É impossível falar que Gonçalves Dias tenha sido pós-arcádico. O que o poeta fez foi continuar inserindo na tradição lírica do Ocidente, manifestações nacionais, condição que já surgira nos melhores árcades brasileiros (como Manuel Inácio da Silva Alvarenga), fazendo novas variações poéticas de temas já consagrados. A meditação, a contemplação do mundo e a busca pela eternidade são alguns destes tão refletidos temas da cultura poética do Ocidente. A solidão e a melancolia também estão muito presentes em seus versos, como nestes, do poema “Arpejos”:

Da noite no remanso

Minha alma se extasia,

E praz-me a sós comigo

Pensar na solidão;

Deixar arrebatar-me 
De vaga fantasia,

Deixar correr o pranto

Do fundo coração.

(DIAS, 1941, p. 332).

Além de ter trabalhado com esses temas, vale a pena lembrar o combate feito, no contexto independentista, por Gonçalves Dias, ao excesso de lusitanismo na linguagem, defendendo o direito brasileiro de aumentar e diferenciar o léxico, a sintaxe e a prosódia do idioma português. A linguagem de sua poesia é simples, direta, e nisto já foi dito que se assenta aos modelos neoclássicos (o que mostra como o poeta não despreza, aliás recomenda o estudo dos autores clássicos), mas também, na opinião de Afrânio Coutinho (1974, p. 62), Gonçalves Dias “defende a língua do povo”, pois "se a literatura é a linguagem carregada de significado, a língua que mais convém à literatura de um povo é aquela que esse povo fala e entende”. E sobre a permanência do substrato tupi, Gonçalves Dias (1974, p. 65) defende que, de "bom ou mau grado, a língua tupi lançou profundíssimas raízes no português que falamos e nós não podemos, nem deveríamos atirá-lo para um canto a pretexto de que a outros parecem bárbaros e mal soantes”.

\section{O indianismo na obra de Gonçalves Dias}

Após copiar modelos externos, de origem europeia, o Romantismo ganha forte cunho nacional com as práticas indianistas. O Romantismo brasileiro possui a peculiaridade indianista devido ao momento histórico em que, após algumas décadas da Independência política, deveria ser feita outra independência, esta pela particularização dos símbolos da sua cultura. No Brasil, a valorização estética do autóctone culminou numa escola literária de importante expressão, buscando motivos locais para a expressão artística. O universo dos povos autóctones na literatura, entretanto, não condiz com a realidade histórica, já que, numa variação do mito do bom selvagem, de origem iluminista, o ameríndio brasileiro é uma criação artificial, ou seja, um ser idealizado.

A exploração dos temas autóctones, quando evocados nos poemas de Gonçalves Dias, pode ser interpretada enquanto tentativa de representação da Idade Média americana, derivação da poética romântica europeia, na qual o período medieval possuiu grande relevância composicional. ${ }^{1} \mathrm{O}$ "índio” é então erigido em símbolo nacional e aparece representado idealisticamente nas mais variadas artes, sendo de "bom tom", para a elite social, aderir ao tema. Exemplo disso são os nomes de importantes jornais da época: Tamoio e Caramuru. Nelson Werneck Sodré sintetiza o fenômeno indianista na sociedade brasileira: ${ }^{2}$
${ }^{1}$ Ferdinand Denis (1978) já assegurara, vendo a questão medieval brasileira por outro viés, que há analogias entre os ideais da cavalaria com os primeiros exploradores das terras brasileiras: elementos da poética cavalheiresca, como a coragem de enfrentar ambientes desconhecidos (as florestas inexploradas, por exemplo), o combate a animais fantásticos (para os europeus, a fauna brasileira é um arcabouço de criaturas míticas), e a honra de guerrear contra nações temíveis (os povos autóctones)

2 Nelson Werneck Sodré (1964) pensa a literatura enquanto parte integrante do processo social. $\mathrm{Na}$ Introdução da sua História da literatura brasileira estabelece uma genealogia de pensadores críticos que já haviam enfocado a literatura com a consciência de integrar o sistema literário ao sistema social "especialmente Sílvio Romero e José Veríssimo, sentiram a importância do problema e, subordinados ainda nisso às condições do tempo, procuram mostrar as íntimas ligações existentes entre a manifestação literária e o meio social. Não se submeteram, entretanto, a um método, não fizeram disso a norma, o 
A força de tais sentimentos, muito maior do que hoje podemos supor, uma vez que estavam ancorados na estrutura social e por ela condicionados, foi tão intensa e penetrou tão fundo no espírito nacional que ainda em nossos dias os indianistas não desapareceram de todo, conquanto, como escola literária, tais manifestações tivessem sido praticamente encerradas duas décadas antes do fim do século XIX. (SODRÉ, 1964, p. 275).

Se foi José de Alencar quem garantiu a generalização do gosto pela literatura de tipo indianista, Gonçalves Dias também ajudou a eternizar esses motivos incorporando-os à poética literária. Antonio Candido afirma que ao poeta maranhense:

Coube, na linha central de formação da nossa literatura [...] promover a realização do tema reputado nacional por excelência [...] sua poesia americana (é o nome dado por ele) que coroa os esforços medíocres de Porto-Alegre e Norberto, em seguimento a "Nênia” tão influente de Firmino Rodrigues. (CANDIDO, 2013, p. 403).

Em certa medida, confluindo com a poética inspirada em composições medievais, as poesias americanas buscaram na história da nação matéria para a literatura. No Brasil, país sem Idade Média, coube aos povos autóctones serem reduzidos aos modelos da cavalaria. Levando em conta esse traço específico, que consiste em rememorar liricamente o tempo de outrora, torna-se possível alinhar poemas de Gonçalves Dias como “O soldado espanhol” com “Os timbiras”. Seguindo nesta linha de produção artística, na qual há apropriação do ideário europeu, que é empregado na poesia brasileira, é interessante notar como certas caracterizações do ameríndio coincidem com modelos europeus das classes nobres: assim, a sua incompatibilidade à condição servil, a “ociosidade”, a sua falta de previdência material, o ânimo para guerras e atividade predatórias.

Em poemas como "I-Juca Pirama”, Gonçalves Dias acentua, na sua configuração poética, elementos relacionados com a caracterização das personagens via caráter heroico, algo já presente nas gerações precedentes, por exemplo, enquanto paradigma composicional de poemas do neoclassicismo. Assim, Antonio Candido (2013, p. 404), na sua leitura da obra de Gonçalves Dias, conclui que “ele procura nos comunicar uma visão geral do índio, por meio das cenas ou feitos ligados à vida de um índio qualquer, cuja identidade é puramente convencional e apenas funciona como padrão”. Tal concepção sublimada do ameríndio brasileiro pode ser encontrada, por exemplo, nos versos da segunda estrofe da "Canção do Tamoio”:

Um dia vivemos!

O homem que é forte

Não teme da morte;

Só teme fugir; caminho natural”

Na sequência,

Nelson Werneck

Sodré, expõe o seu

método de trabalho, citando György

Lukács: "Pensamos que "a formação e o desenvolvimento da literatura são uma parte do processo histórico total da sociedade. A essência e o valor estético das obras literárias, e também de sua ação, é uma parte do processo histórico geral e unitário pelo qual o homem se apropria do mundo mediante a sua consciência”. (SODRÉ, 1964, p. 3). 
No arco em que enteza

Tem certa uma presa,

Quer seja tapuia,

Condor ou tapir. ${ }^{3}$

(DIAS, 1941, p. 300).

Quanto à despersonalização do ameríndio na obra poética de Gonçalves Dias, isto não quer dizer que esta estratégia composicional seja vazia de sentido. Pelo contrário, trata-se de uma configuração que, na sua concisão, consegue ser plena de sentido, quando vista pelo prisma da construção nacional de verve romântica, em que o "sentimento de honra” era a mais estimada característica e ela deveria estar presente em todo e qualquer brasileiro. O elemento heroico, outro traço desejado pela ideologia nacional, aparece em "I-Juca Pirama”, poetizado através dos mais diversos ritmos, com imagens de convenção que satisfazem a proposta romântica de construção do caráter nacional:

Aqui, porém, o poeta inventou um recurso inesperado e excelente: o lamento do prisioneiro, caso único em nosso Indianismo, que rompe a tensão monótona da bravura tupi graças à supremacia da piedade filial:

Guerreiros não coro

Do pranto que choro (CANDIDO, 2013, p. 405).

Além disso, as “poesias americanas” estão permeadas por elementos organizados poeticamente para diferenciar a vida brasileira das demais por causa, além da presença dos povos autóctones com os seus costumes e a sua sociedade de integração tribal, da natureza americana. O êxtase perante o Novo Mundo cria uma estética singular, por sua compreensão (modalizada pelo pensamento romântico europeu) do detalhe pitoresco americano. Neste contexto, de exaltação da paisagem brasileira, entra a famosa “Canção do exílio”:

\footnotetext{
Minha terra tem palmeiras,

Onde canta o Sabiá;

As aves, que aqui gorjeiam,

Não gorjeiam como lá.
}

(DIAS, 1941, p. 22).

Entretanto, é necessário também levar em conta que a atividade literária nacional estava, no século XIX, estreitamente vinculada às práticas culturais da classe dominante que, num contexto independentista, buscava sobremaneira diferenciar-se dos portugueses: o que é brasileiro deveria ser rigorosamente diverso do que é lusitano. Consequentemente, por tal motivo o "índio” servia de fundamento para uma prática literária agressiva em relação aos valores lusitanos: “fora ele [o autóctone] o adversário do

${ }^{3}$ Antonio Candido (2013, p. 404), a seguir, compara o emprego indianista de Gonçalves Dias com a figuração do índio nos romances de Alencar, autor que "procura transformálo em personagem, particularizando-o e, por isso mesmo, tornando-o mais próximo à sensibilidade do leitor". 
português colonizador - ele que, dono da terra, e livre nessa terra, opusera-se ao domínio luso, lutara contra ele, e fora derrotado combatendo”. (SODRÉ, 1964, p. 279).

Portanto, os elementos, todos eles presentes na obra de Gonçalves Dias, capazes de especificar a prática do indianismo, podem ser os seguintes: 1) o elemento folclórico, estudado por Capistrano de Abreu e citado por José de Alencar em Como e porque sou romancista; 2) a influência estrangeira (Chateaubriand, sobretudo, e Cooper); 3) o nativismo antilusitano, valorizando a resistência ameríndia ao colonizador europeu; 4) a impossibilidade de eleger o negro como herói nacional, devido à perversa necessidade econômica do sistema escravista; 5) o elemento idiomático, visando diferenciar o português brasileiro do português europeu.

\section{Considerações finais}

Gonçalves Dias foi um grande poeta brasileiro capaz de aliar tradição e inovação numa obra relativamente extensa. Interpretá-lo, somente por seus elementos indianistas e nacionalistas, acaba por excluir toda uma complexidade que faz dele um poeta maior. As interpretações de Antonio Candido e de Nelson Werneck Sodré deixam isto claro: Gonçalves Dias foi um poeta romântico que soube aproveitar o que ainda possuía vigor na estética neoclássica, como a clareza e a harmonia do verso; e deixar de fora convenções já desgastadas na cultura europeia, tais como as figuras e lugares mitológicos de matriz greco-latina. O que foi descartado acabou sendo substituído por representações nacionais, fazendo com que a sua poesia imbrique temas universais e variações brasileiras.

\section{Referências}

BOUTERWEK, Friedrich. Antonio José e Cláudio Manuel da Costa. Tradução de Guilhermino César. In: CÉSAR, Guilhermino (Org.). Historiadores e críticos do Romantismo. Rio de Janeiro/São Paulo: ETC/EDUSP, 1978.

CANDIDO, Antonio. Formação da literatura brasileira. Rio de Janeiro: Ouro sobre Azul, 2013.

CÉSAR, Guilhermino (Org.). Historiadores e críticos do Romantismo. Rio de Janeiro/São Paulo: ETC/EDUSP, 1978.

COUTINHO, Afrânio (Org.). Caminhos do pensamento crítico. Rio de Janeiro: Pallas, 1974.

DENIS, Ferdinand. Resumo da história literária do Brasil. Tradução de Guilhermino César. In: CÉSAR, Guilhermino (Org.). Historiadores e críticos do Romantismo. Rio de Janeiro/São Paulo: ETC/EDUSP, 1978. 
DIAS, Gonçalves. Obras completas. São Paulo: Edições Cultura, 1941.

Carta ao Dr. Pedro Nunes Leal. In: COUTINHO, Afrânio (Org.).

Caminhos do pensamento crítico. Rio de Janeiro: Pallas, 1974.

GARRETT, Almeida. Parnaso lusitano. In: ZILBERMAN, Regina; MOREIRA, Maria Eunice (Orgs.). O berço do cânone. Porto Alegre: Mercado Aberto, 1998.

MAGALHÃES, Gonçalves de. Discurso sobre a história da literatura brasileira. In: COUTINHO, Afrânio (Org.). Caminhos do pensamento crítico. Rio de Janeiro: Pallas, 1974.

SISMONDI, Sismonde de. De la littérature du Midi de l’Europe. Tradução de Guilhermino César. In: CÉSAR, Guilhermino (Org.). Historiadores e críticos do Romantismo. Rio de Janeiro/São Paulo: ETC/EDUSP, 1978.

SODRÉ, Nelson Werneck. História da literatura brasileira (Seus fundamentos econômicos). Rio de Janeiro: Civilização Brasileira, 1964.

Enviado em agosto/2018.

Aceito em fevereiro/2019. 